\title{
Researchers resist copyright laws that could endanger data access
}

Washington. Researchers across the world could lose access to important databanks under new database copyright rules being considered by the World Intellectual Property Organisation (WIPO), scientific leaders in the United States warned last week.

The critics say that, in order to use data under the proposed rules, astronomers, climatologists, oceanographers and others who rely on free access to large observational databases would have to seek permission and perhaps to pay. The proposed rules are said to have originated in Europe and have already been endorsed by the US Department of Commerce.

But US government lawyers say that the concerns are misplaced. According to one of them, Keith Kupferschmid of the US Patent and Trademark Office (PTO), scientists will get free access to data anyway under the proposed law, because their using it will not do "substantial harm" to the commercial interests of the database compiler.

Leaders of the US scientific establishment have written to Michael Kantor, secretary of commerce, criticizing the proposed new rules. They want the United States to withdraw its support and to prevent their endorsement at a planned WIPO meeting in Geneva in December.

In the letter, Bruce Alberts, president of the National Academy of Sciences, William Wulf, president of the National Academy of Engineering, and Kenneth Shine, of the Institute of Medicine, say that the proposed changes would "significantly inhibit researchers seeking to reuse and combine data for publication or for research".

The changes were endorsed by the commerce department "without any debate or analysis of the law's potentially harmful implications" for science and technology, the letter says. It points out that, although the unintended consequences appear "very grave", no effort was made to consult the scientific community.

The proposals would assign the copyright on the contents of a database to whoever compiled it, require users to ask for permission to use the contents, and set up a basis for payment for use. Critics say that the law would apply to all privately generated datasets, as well as to public datasets from countries that wished to restrict access.

Climate scientists are particularly worried that cash-strapped weather services in some countries could use the rule to extract fees from researchers who need access to their weather records. According to John Barton of the law school at Stanford University, the privatization of satellite and other datagathering operations will place an increasing quantity of vital data in the hands of organizations that will be inclined to use the new law to charge scientists for access. "The entire community ought to be very upset about this," says Wulf.

Stephen Berry, a chemist at the University of Chicago, attacks the proposal for failing to include any "fair use" provision of the type that currently allows free use of documents and databases for research. In the worst scenario, he says, the proposal would allow a commercial database compiler to "co-opt" publicly accessible data and claim copyright on it.

According to Berry, the proposal won the backing of the United States because commercial publishers exerted their influence before scientists became aware of what was happening. He now hopes that pressure from scientists can prevent the WIPO meeting from endorsing the plan.

Scientists have been alerted to the issue by the computer data committee of the International Council of Scientific Unions, and are pushing for changes to protect the principle of free access to data for research.

Bruce Lehman, commissioner of the PTO, was due to meet Alberts, Wulf and Shine this week to discuss their concerns. Kupferschmid of the PTO says that databases will be protected only where a substantial investment has been made and the use would substantially harm that investment. He adds that "most of US commerce and industry is happy with the proposal".

WIPO will meet for three weeks in December to consider three new international treaties to protect databases, literary and artistic works and music recordings respectively. Each treaty will require ratification by signatories - by the Senate, in the case of the United States.

But the academies' letter to Kantor warns that anything adopted by WIPO "will move substantially toward becoming the new international norm" by the end of this year - regardless of US Senate ratification. The PTO will hold a forum to discuss the draft proposals in Arlington, Virginia, on 12 November.

\section{Massive star comes into bright focus}

London. The orbiting Hubble Space Telescope has captured rare images of a giant star (right), which is 30 to 60 times as massive as the Sun and whose brightness has increased 40-fold in the past three years. The star belongs to a class known as erupting luminous blue variables (LBV) and is still in a very unstable and eruptive period of its life.

The star is the largest of a cluster of erupting stars and luminescent gases distributed in the shape of a fish-hook. All are contained in the Magellanic galaxy NGC2366, about 10 million light years from Earth.

The Hubble image shows two further dense clusters of massive stars. The older cluster at the top of the picture is around 4 to 5 million years old. It is relatively dim, having lost its luminescent gases to the effects of stellar 'winds' and supernova blasts. The younger and brighter cluster (bottom centre) is probably less than $\mathbf{2}$ million years old.

\section{IMAGE UNAVAILABLE FOR COPYRIGHT REASONS}

Only four LBV eruptions have been recorded. This latest eruption was first spotted at the beginning of the year. The rate of increase in its brightness was measured by comparisons with previous ground-based images. 